\title{
AVALIAÇÃO DO BOMBEAMENTO DE ÁGUA EM UM SISTEMA ALIMENTADO POR PAINÉIS FOTOVOLTAICOS
}

\section{ROGER N. MICHELS ${ }^{1}$, REINALDO P. RICIERI ${ }^{2}$, ESTOR GNOATTO ${ }^{3}$, SAMUEL N. M. DE SOUSA ${ }^{4}$, SUEDÊMIO DE LIMA SILVA ${ }^{5}$, MARCOS FISCHBORN ${ }^{6}$}

\begin{abstract}
RESUMO: O presente trabalho foi desenvolvido com a finalidade de avaliar um sistema de bombeamento de água acionado por painéis fotovoltaicos instalados nas dependências da Universidade Tecnológica Federal do Paraná, Câmpus Medianeira - PR. O município está localizado no oeste paranaense $\left(25^{\circ} 17^{\prime} 43^{\prime \prime}\right.$ S; $54^{\circ} 03^{\prime} 38^{\prime \prime}$ e $\left.500,7 \mathrm{~m}\right)$. O sistema trabalhou em situação real de funcionamento, bombeando água à altura de $20 \mathrm{~m}$. Foram coletados dados de fevereiro a novembro de 2005; utilizou-se coletor de dados computadorizado da Campbell Scientific INC., que possibilitou adquirir e armazenar os dados de irradiância solar no plano do painel, tensão e corrente gerada, temperatura no painel e vazão. Por meio de cálculos, obtiveram-se os valores de potência e eficiência do sistema. O solstício de inverno apresentou eficiência de 9,58\% com bombeamento diário de 2.056 litros, enquanto o solstício de verão apresentou eficiência de 9,07\% com bombeamento diário de 2.377 litros. A maior eficiência nos dias de inverno está ligada às menores temperaturas se comparada aos dias de verão, e o fator que provocou a maior vazão de água bombeada nos dias de verão está atrelado ao tempo de insolação, que é maior se comparado aos dias de inverno.
\end{abstract}

PALAVRAS-CHAVE: bombeamento, energia, fotovoltaica, eficiência.

\section{WATER PUMPING IN A SYSTEM FED BY PHOTOVOLTAIC PANELS}

\begin{abstract}
The main objective of this paper is to evaluate a water pumping system powered by photovoltaic panels installed at Federal Technological University of Paraná - UTFPR, in

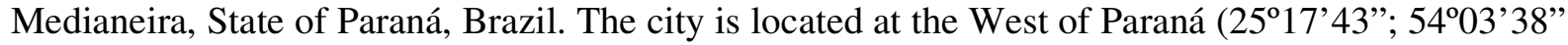
and 500.7 meters - 1,642.72 feet). The system operated in a real working situation, pumping water to 20 meters (65.62 feet) of elevation. The data were collected, from February 2005 to November 2005, by means of a computerized data collector made by Campbell Scientific Inc that made possible to acquire and store irradiance values in the panel plane, generated current and voltage, panel temperature and outflow. Through calculations, the power and the system efficiency were obtained. Winter solstice showed $9.58 \%$ efficiency with daily pumping of 2,056 liters (543.14 gallons) whereas summer solstice confirmed $9.07 \%$ efficiency with daily pumping of 2,377 liters (627.86 gallons). The higher efficiency in winter days is associated to the lowest temperature in those days compared to summer days, and the factor that led to a larger pumped water outflow in the summer days was related to solar insolation time that is longer if compared to winter days.
\end{abstract}

KEYWORDS: pumping, energy, photovoltaic, efficiency.

\footnotetext{
${ }^{1}$ Prof. Colaborador, Universidade Tecnológica Federal do Paraná - UTFPR, Medianeira - PR, rogernmichels@yahoo.com.br

${ }^{2}$ Prof. Adjunto, Universidade Estadual do Oeste do Paraná - UNIOESTE, Cascavel - PR.

${ }^{3}$ Prof. Adjunto, Universidade Tecnológica Federal do Paraná - UTFPR, Medianeira - PR.

${ }^{4}$ Prof. Adjunto, Universidade Estadual do Oeste do Paraná - UNIOESTE, Cascavel - PR.

${ }^{5}$ Prof. Adjunto, Universidade Federal Rural do Semiárido - UFERSA, Mossoró - RN.

${ }^{6}$ Prof. Adjunto, Universidade Tecnológica Federal do Paraná - UTFPR, Medianeira - PR.

Recebido pelo Conselho Editorial em: 3-9-2007
}

Aprovado pelo Conselho Editorial em: 13-7-2009 


\section{INTRODUÇÃO}

O setor agrícola vem desenvolvendo-se devido à pesquisa e à implementação de novas tecnologias que acarretam maior consumo de energia. Atualmente, a geração de energia no Brasil é, em sua maioria, sinônimo de impacto ambiental, por serem utilizadas fontes convencionais, como o petróleo e as hidroelétricas.

A forma de geração de energia elétrica mais utilizada no Brasil é a hidroelétrica, considerada uma fonte limpa, mas que também provoca danos. KAWAHARA (2003) afirma que "...o Brasil é um dos países que detêm as maiores bacias hidrográficas, cuja energia elétrica proveniente de energia hidráulica também é limitada e ainda causa grandes inundações para a formação dos reservatórios, em áreas que poderiam produzir mais alimentos, pois nesses locais os solos são mais ricos para a agricultura".

A resolução do Conselho Nacional do Meio Ambiente - CONAMA (1986), considera impacto ambiental como “...qualquer alteração das propriedades físicas, químicas e biológicas do meio ambiente, causada por qualquer forma de matéria ou energia resultante das atividades humanas que, direta ou indiretamente, afetam a saúde, a segurança e o bem-estar da população, as atividades sociais e econômicas, a biota, as condições estéticas e sanitárias do meio ambiente, a qualidade dos recursos ambientais".

Uma solução para esses fenômenos seria a utilização de fontes alternativas de energia, como a energia solar, que pode trazer grande ajuda para a diminuição do impacto ambiental que as fontes convencionais provocam, como a poluição atmosférica, o aquecimento global, entre outros.

Atualmente, a fonte solar de energia é utilizada para o aquecimento d'água, desidratação de frutas, legumes e ervas; com a tecnologia dos painéis fotovoltaicos, é possível a sua utilização em estações espaciais, satélites de telecomunicações, estações meteorológicas, faróis de sinalização, eletrificação rural, entre outros. Porém, o rendimento de um painel fotovoltaico é baixo, sendo necessário estudo dirigido para sua aplicação.

A energia solar fotovoltaica está difundida em várias localidades do Brasil, aplicada a diversas finalidades. Por se tratar de fonte versátil, pode ser utilizada em locais remotos onde a rede elétrica não é compensatória, sendo uma opção para pequenos agricultores.

Uma aplicação dessa forma de energia é o bombeamento de água, representando solução às famílias residentes em pequenas propriedades em regiões áridas e semiáridas. Para essa aplicação, é imprescindível conhecer a tensão, a corrente e, consequentemente, a potência gerada pelos painéis, tensão e potência necessárias para o acionamento da bomba, a irradiação média da região em todas as estações do ano e a vazão de água fornecida pela motobomba para definir sua utilização.

O objetivo deste experimento foi o de analisar um sistema de bombeamento de água alimentado por dois painéis fotovoltaicos instalados em Medianeira, região oeste do Paraná, determinando o rendimento e a potência do painel, definindo o ponto de estabilização do sistema e verificando o comportamento do sistema nos períodos de solstício.

\section{MATERIAL E MÉTODOS}

Para a montagem do sistema de bombeamento de água com o conjunto fotovoltaico, foram necessários os seguintes equipamentos:

Dois painéis solares, fabricante Solarex, modelo MSX 56, tensão-padrão de 12 V, corrente-padrão de 3,35 A e potência de $56 \mathrm{~W}$;

- uma bomba, fabricante SolarJack, modelo SDS-D-228, tensão de 30V;

- um medidor de vazão, fabricante LAO, tipo turbina, classe 0,1 ;

- um transdutor de vazão aferido com precisão;

- um micrologger da marca Campbel Scientific-INC, modelo CD23X;

- um termopar do tipo K (cromo/alumínio) aferido para a aquisição de dados;

Eng. Agríc., Jaboticabal, v.29, n.3, p.370-379, jul./set. 2009 
- um piranômetro Kipp \& Zonen CR23;

- um divisor de tensão, e

- uma resistência Shunt.

Foram instalados dez painéis fotovoltaicos, sendo que apenas dois painéis foram utilizados, ligados em série, devido à configuração do sistema. Uma bomba do tipo diafragma foi alimentada pelos dois painéis e bombeou água à altura de $20 \mathrm{~m}$, altura entre a cisterna e a caixa d'água onde está instalada.

Teve-se maior preocupação com o posicionamento dos painéis em relação ao seu alinhamento com o norte geográfico, pois seu posicionamento incorreto pode acarretar na diminuição da eficiência do sistema fotovoltaico. Para isso, foi determinado o horário oficial do meio-dia real para o dia do alinhamento, no caso, 9 de novembro de 2004. O valor do meio-dia real foi determinado por meio do site da LECT - Laboratório de Ensino de Ciências e Tecnologia (2006) (latitude sul de

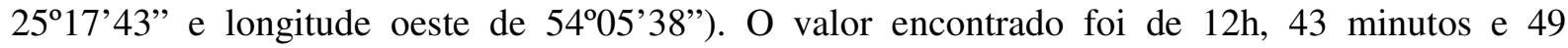
segundos. Com o valor do meio-dia real, foi possível determinar o norte geográfico e, consequentemente, o posicionamento do conjunto fotovoltaico pela sombra de uma haste vertical projetada sobre um plano horizontal.

Outra preocupação foi com o ângulo necessário entre o painel e o plano horizontal em que está apoiado. GNOATTO (2003) sugere que os módulos sejam instalados com ângulo igual à latitude do local de instalação. Tal inclinação é importante para evitar o acúmulo de sujeira e para obter maior eficiência do sistema fotovoltaico devido à maior exposição à radiação solar, principalmente no período de inverno. Na Figura 1, mostra-se o sistema fotovoltaico.

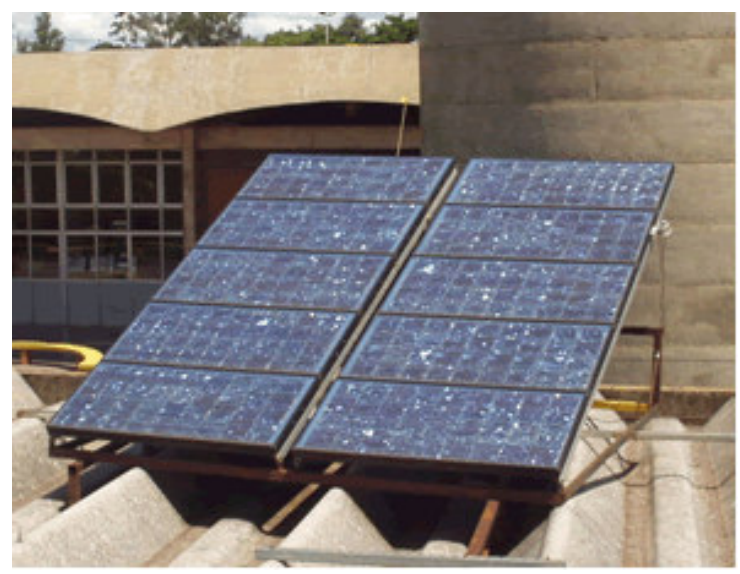

FIGURA 1. Conjunto fotovoltaico. Photovoltaic set.

Para a realização do estudo, foi necessária a instalação de equipamentos para aquisição e armazenamento de dados para posterior avaliação. Foram obtidas as seguintes informações:

- irradiação solar global incidente nos painéis fotovoltaicos;

- vazão da água proporcionada pela bomba;

- tensão e corrente emitidas pelos dois painéis fotovoltaicos, e

- temperatura nos painéis fotovoltaicos.

Foram coletados dados de $1^{\mathrm{o}}$ de fevereiro a 30 de novembro de 2005; as leituras ocorriam a cada 5 segundos, sendo os dados gravados no computador com média a cada minuto.

Os equipamentos foram ligados a coletor de dados computadorizado (Datalogger) onde ocorreu a aquisição e a armazenagem dos dados de tensão, corrente, vazão, temperatura e irradiância. Na Figura 2, observa-se o Datalogger com a entrada de todos os transdutores. 


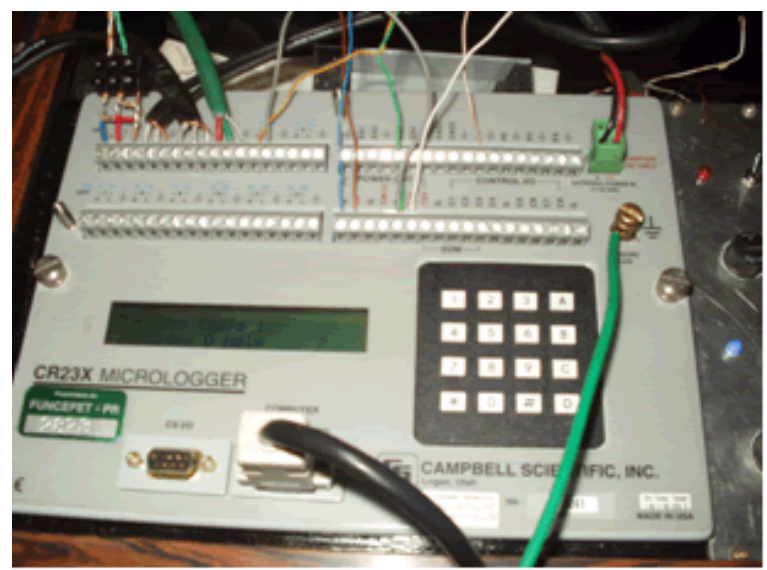

FIGURA 2. Datalogger CR 23X da Campbel Scientific Int. Dattalogger CR 23X model from Campbel Scientific Int.

Para a obtenção dos valores de potência gerada pelos painéis fotovoltaicos, multiplicaram-se os valores de tensão pela corrente, eq.(1):

$$
\mathrm{P}=\mathrm{V} \mathrm{I}
$$

A eficiência do sistema foi obtida por meio da eq.(2) (CAMUS \& EUSÉBIO, 2006):

$$
\eta=\frac{\mathrm{V} \mathrm{I}}{\text { Is A }} 100
$$

em que,

V - tensão, V;

I - corrente, A;

Is - irradiação solar global, $\mathrm{Wm}^{-2}$, e

A - área útil do módulo, $\mathrm{m}^{-2}$.

\section{RESULTADOS E DISCUSSÃO}

Para a análise dos dados, foram selecionados dois dias de céu limpo, ou seja, sem a influência de nuvens, em estações do ano opostas e o mais próximo dos solstícios de inverno e de verão. Os dois dias selecionados foram 3 de julho de 2005, para o solstício de inverno, e 26 de novembro de 2005, para o solstício de verão. Para a análise de vazão, utilizou-se todo o período de coleta de dados.

\section{Irradiância solar}

Ao analisar os dados do dia 3 de julho de 2005, verificou-se que o início da irradiância solar se dá às $7 \mathrm{~h} 25 \mathrm{~min}$, estendendo-se até às $18 \mathrm{~h} 04 \mathrm{~min}$, atingindo seu valor máximo às $12 \mathrm{~h} 54 \mathrm{~min}$ com o valor de $907 \mathrm{Wm}^{-2}$. Já para o dia 26 de novembro de 2005, o início da irradiância solar ocorre às $6 \mathrm{~h} 45 \mathrm{~min}$, estendendo-se até às $18 \mathrm{~h} 47 \mathrm{~min}$, com valor máximo de $1.070 \mathrm{Wm}^{-2}$ às $12 \mathrm{~h} 28 \mathrm{~min}$. Essas afirmações podem ser vistas na Figura 3.

Por meio desse gráfico, pôde-se ainda comprovar que os dois dias analisados estavam livres da influência de nuvens, provando que os dias analisados possuíam céu limpo. 


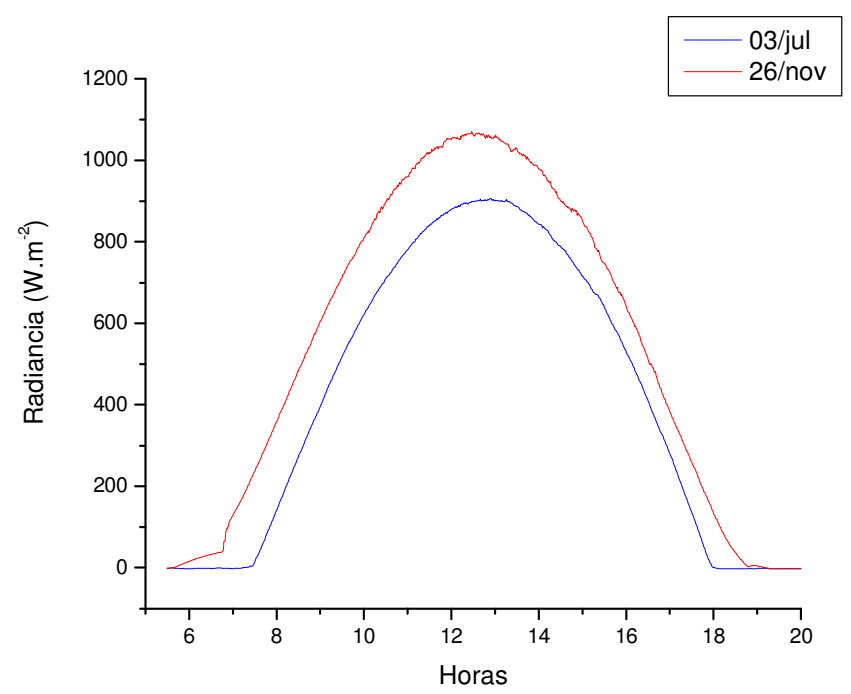

FIGURA 3. Irradiância solar no plano do painel fotovoltaico. Solar irradiance in the photovoltaic panel plane.

\section{Corrente e tensão}

Os valores de corrente elétrica do sistema foram obtidos com o auxílio de resistência Shunt, e pela Figura 4, verificou-se o seu comportamento para os dias analisados. Nota-se que, para o dia 3 de julho de 2005, o ponto de estabilização da corrente iniciou-se às $9 \mathrm{~h} 36 \mathrm{~min}$, estendendo-se até às 15h53min, com valor médio de 1,60 A. Já para o dia 26 de novembro de 2005, a estabilização iniciou-se às $8 \mathrm{~h} 42 \mathrm{~min}$, estendendo-se até às 16h13min, com valor médio de 1,56 A.

De acordo com METWALLY \& ANIS (1996), que avaliaram um sistema constituído por um painel fotovoltaico, um motor de corrente contínua e uma bomba centrífuga, a corrente estabilizou-se com o valor de 1,56 A e com irradiância solar de $350 \mathrm{Wm}^{-2}$.

Para o dia 3 de julho, levando em conta o horário de início de estabilização e observando a Figura 3, averiguou-se que a estabilização da corrente iniciou-se com valor de irradiância solar de $541,4 \mathrm{Wm}^{-2}$ e para o dia 26 de novembro, este valor é de $530 \mathrm{Wm}^{-2}$.

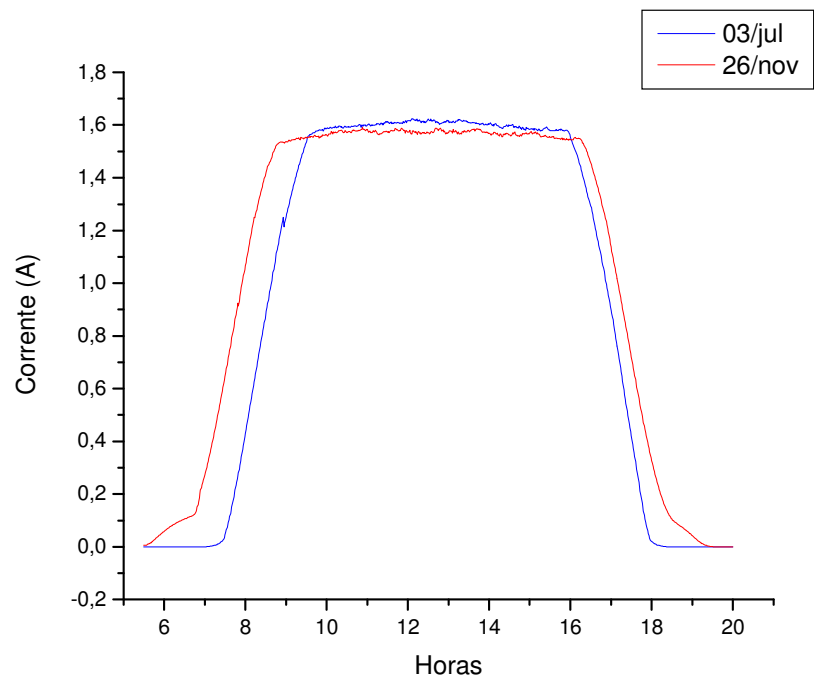

FIGURA 4. Corrente do sistema para dois dias de céu limpo nos solstícios de inverno e de verão. System current for two clean days in the winter and summer solstices. 
A tensão, assim como a corrente, possui um ponto de estabilização que, para o dia 3 de julho de 2005 , teve início às $10 \mathrm{~h}$ e seu término às $15 \mathrm{~h} 33 \mathrm{~min}$, com valor médio de $33,32 \mathrm{~V}$ e temperatura média de $47,12^{\circ} \mathrm{C}$. Para o dia 26 de novembro de 2005 , o início da estabilização ocorreu às $9 \mathrm{~h} 11 \mathrm{~min}$, estendendo-se até às $16 \mathrm{~h} 06 \mathrm{~min}$, com valor médio de $32,62 \mathrm{~V}$ e temperatura média de $54,29^{\circ} \mathrm{C}$, como é visto na Figura 5. A irradiância solar encontrada para o início da estabilização da tensão para o dia 3 de julho é de $621,6 \mathrm{Wm}^{-2}$ e para o dia 26 de novembro é de $648,5 \mathrm{Wm}^{-2}$.

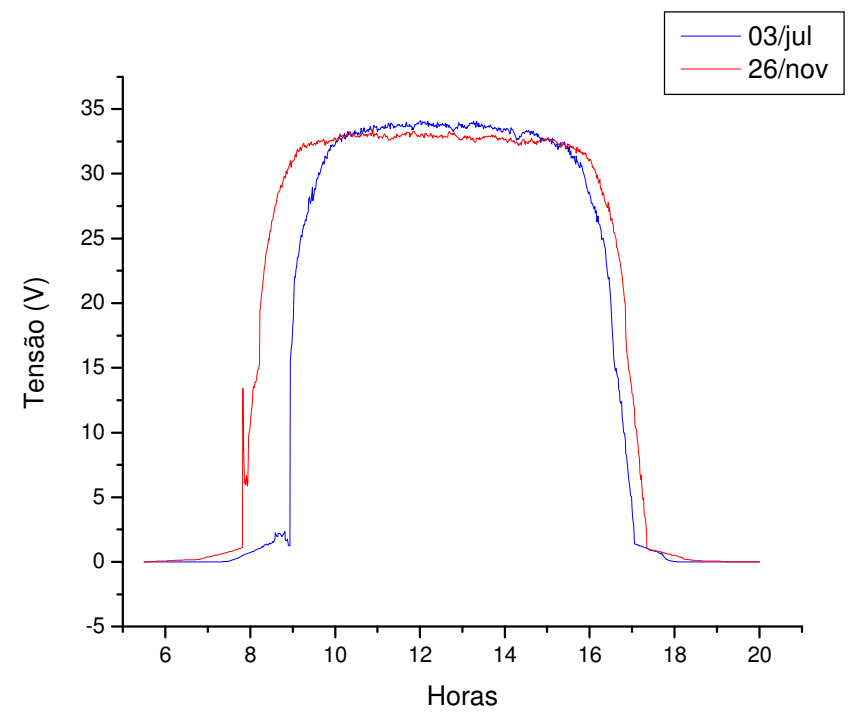

FIGURA 5. Tensão do sistema para dois dias de céu limpo nos solstícios de inverno e de verão. System voltage for two clean days in winter and summer solstices.

\section{Potência}

Para o dia 3 de julho de 2005, o ponto de estabilização da potência ocorreu às $10 \mathrm{~h} 07 \mathrm{~min}$, estendendo-se até às $15 \mathrm{~h} 40 \mathrm{~min}$, com valor médio de $53,32 \mathrm{~W}$, e para o dia 26 de novembro de 2005 , o ponto de estabilização teve início às $9 \mathrm{~h} 07 \mathrm{~min}$, tendo término às $15 \mathrm{~h} 45 \mathrm{~min}$, com valor médio de 51,29 W. O comportamento da potência pode ser visto na Figura 6.

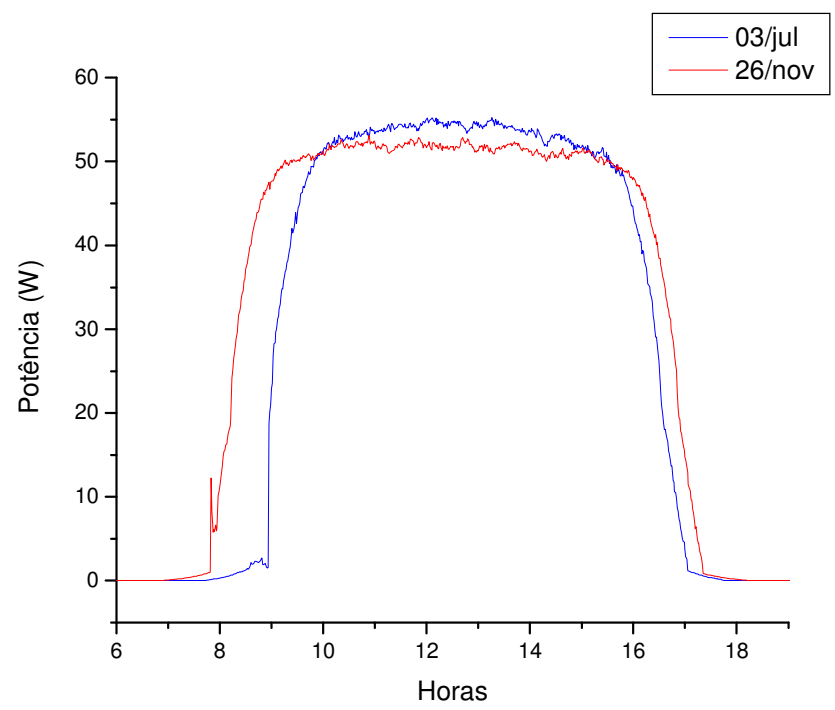

FIGURA 6. Potência do sistema para dois dias de céu limpo nos solstícios de inverno e de verão. System power for two clean days for winter and summer solstices. 


\section{Vazão}

Analisando os valores da vazão por meio da Figura 7, verificou-se que, para o dia 3 de julho de 2005, o sistema inicia o bombeamento às $8 \mathrm{~h} 57 \mathrm{~min}$ e atinge sua estabilização às $9 \mathrm{~h} 51 \mathrm{~min}$, estendendo-se até às $15 \mathrm{~h} 47 \mathrm{~min}$. Durante o período de estabilização, a média da vazão foi de $4,64 \mathrm{~L} \mathrm{~min}{ }^{-1}$. O final do bombeamento acontece às $17 \mathrm{~h} 02 \mathrm{~min}$. Para o dia 26 de novembro de 2005 , o sistema entra em funcionamento às $7 \mathrm{~h} 50 \mathrm{~min}$; o período de estabilização iniciou-se às $9 \mathrm{~h} 11 \mathrm{~min}$, estendendo-se até às $15 \mathrm{~h} 53 \mathrm{~min}$. Durante esse período, a média de vazão foi de 4,59 $\mathrm{L} \mathrm{min}^{-1} \mathrm{e}$ o final do bombeamento acontece às $17 \mathrm{~h} 20 \mathrm{~min}$.

A quantidade de água bombeada pelo sistema para o dia 3 de julho foi de 2.056,44 litros, e mesmo o dia 26 de novembro tendo média de bombeamento de água menor durante a estabilização, apresentou o total de água bombeada de 2.377,21 litros; isso está atrelado à maior quantidade de horas de insolação para os dias de verão, resultando em maior tempo de funcionamento do sistema.

KOLLING et al. (2004), utilizando uma motobomba Shurflo, modelo 2088, bombeando água à altura de $19 \mathrm{~m}$ (a carga era obtida por meio de válvulas que simulavam a altura manométrica), obteve vazão média de $6,52 \mathrm{~L} \mathrm{~min}^{-1}$, com vazão diária de 2.445 litros.

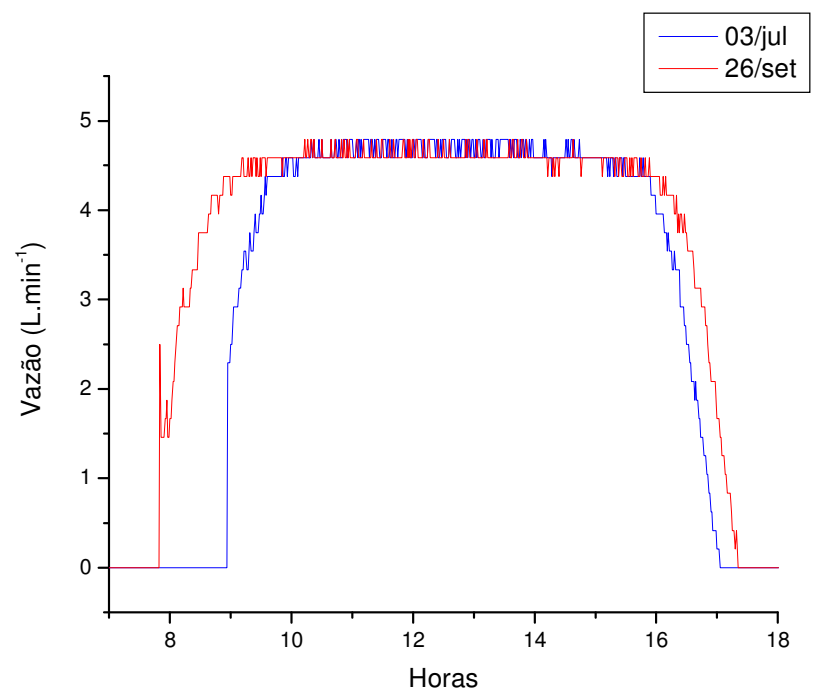

FIGURA 7. Vazão do sistema para dois dias de céu limpo nos solstícios de inverno e de verão. System outflow for two clean days in the winter and summer solstices.

Por meio da Figura 8, pôde-se observar o total de água bombeada para cada mês entre fevereiro e novembro de 2005. Nota-se que, no verão, a quantidade de água bombeada pelo sistema é maior que nos meses de inverno. Esse resultado é devido ao total de insolação existente nos meses de verão; os meses de julho e agosto mostram-se com alta quantidade de água bombeada, mesmo possuindo dias mais curtos. Isso está atrelado à quantidade de chuva, que é reduzida nesses meses.

O mês que apresentou a maior quantidade de água bombeada foi novembro, com 53.053,51 L, e o mês que apresentou a menor quantidade de água bombeada foi junho, com 32.439,59 L. A quantidade total de água bombeada foi de 435.042,20 L. 


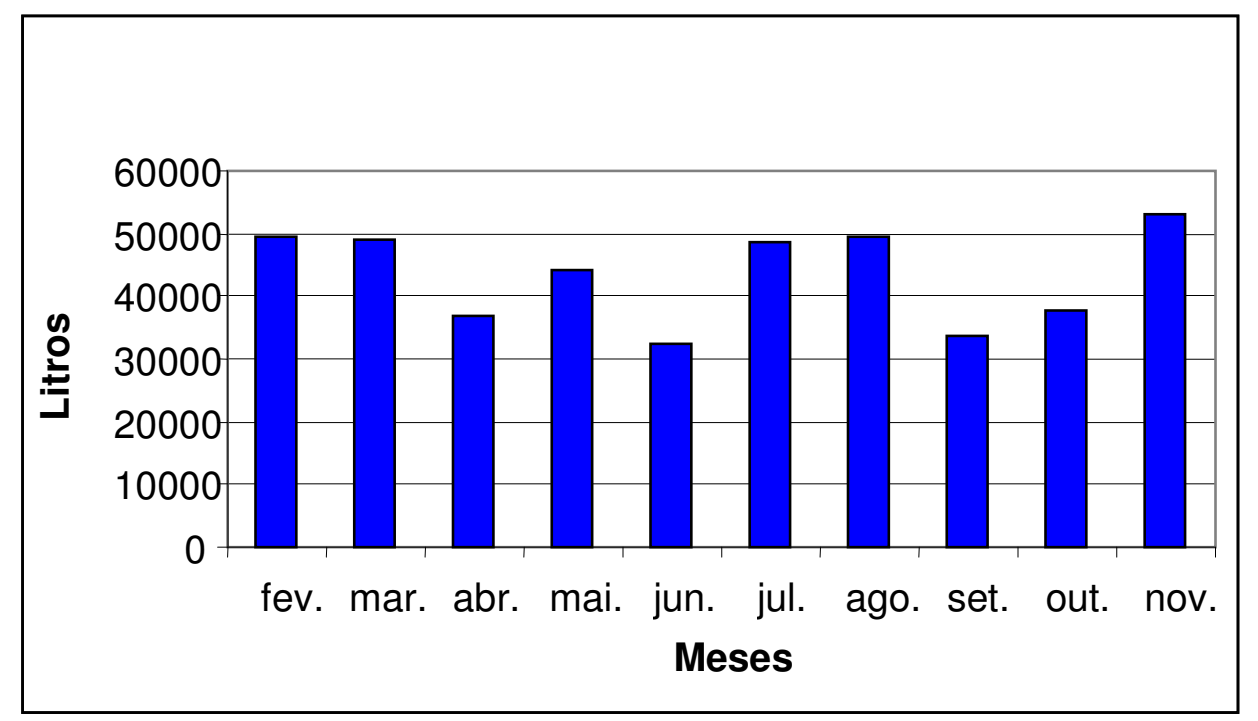

FIGURA 8. Vazão total de água bombeada por mês pelo sistema. Total water outflow pumped monthly by the system.

\section{Temperatura do painel fotovoltaico}

A temperatura máxima para o dia 3 de julho de 2005 foi de $51,16^{\circ} \mathrm{C}$ e atingiu esse valor às 14 h19min. Já para o dia 26 de novembro de 2005 , a temperatura máxima encontrada foi de $59,89{ }^{\circ} \mathrm{C}$ às $13 \mathrm{~h} 19 \mathrm{~min}$, como pode ser observado na Figura 9.

O fator temperatura influencia na potência e, consequentemente, na eficiência do sistema. Segundo GNOATTO et al. (2004), "um módulo fotovoltaico não é fonte linear de potência, depende da temperatura e do nível de radiação". Para contemplar essa informação, GOETZBERGER et al. (1998), citado por RIFFEL (2005), descreve que "A temperatura faz com que a banda de energia do material semicondutor diminua, resultando em acréscimo da fotocorrente gerada de aproximadamente $1 \%$. Entretanto, a tensão de circuito aberto decresce à taxa de $0,3 \%$, resultando que a potência diminua em $1 \%$ a cada $2,7^{\circ} \mathrm{C}$ de elevação de temperatura."

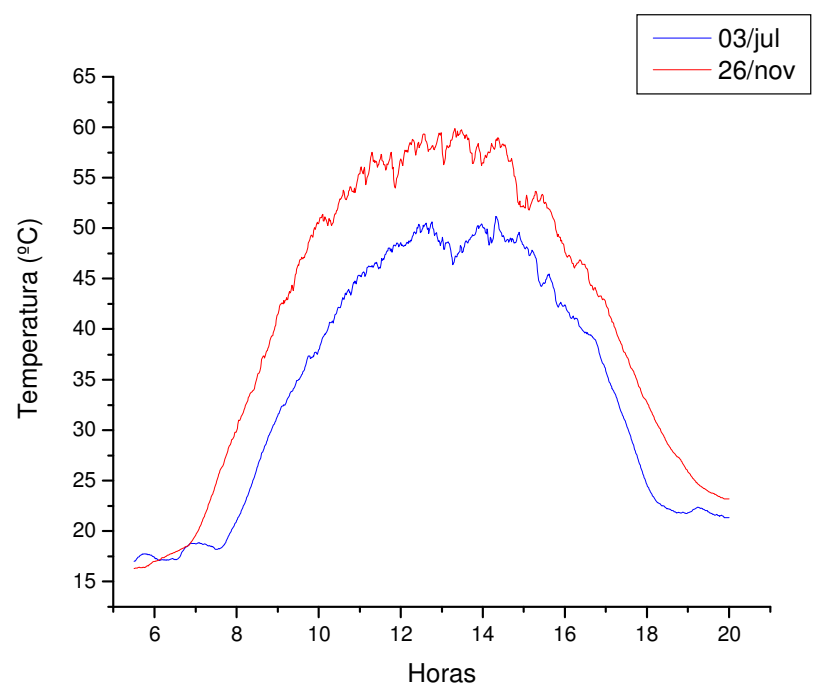

FIGURA 9. Temperatura no painel fotovoltaico. Temperature in the photovoltaic panel. 


\section{Eficiência do sistema de bombeamento de água acionado por painéis fotovoltaicos}

Os valores da eficiência do sistema são encontrados por meio da divisão da potência pela multiplicação da irradiância e da área útil do painel fotovoltaico, cujo valor é de $0,90288 \mathrm{~m}^{2}$, conforme a eq.(2).

Analisando os dados da eficiência para o dia 3 de julho de 2005, encontra-se um pico máximo durante o período da manhã, com valor de $9,58 \%$ às $9 \mathrm{~h} 34 \mathrm{~min}$; a partir desse momento, o valor de irradiância aumenta, diminuindo a eficiência. Esse fenômeno ocorre, pois o painel fotovoltaico já está saturado, ou seja, a partir de aproximadamente $533 \mathrm{Wm}^{-2}$ de irradiância, o painel fotovoltaico não aumenta a conversão, e o excesso de irradiância é dado como perda. No período da tarde, quando a irradiância está decrescendo, a eficiência apresenta outro aumento, e no seu pico máximo, apresentou o valor de $9,34 \%$ às $15 \mathrm{~h} 47 \mathrm{~min}$.

Para o dia 26 de novembro de 2005, o pico máximo encontrado no período da manhã é de $9,07 \%$ às $8 \mathrm{~h} 43 \mathrm{~min}$, e no período da tarde, o valor máximo encontrado é de $8,57 \%$ às $16 \mathrm{~h} 28 \mathrm{~min}$. $\mathrm{O}$ fator que atribui eficiência maior ao dia 3 de julho, comparado ao dia 26 de novembro, é a temperatura, mesmo fator que faz o pico da manhã apresentar valor maior que o da tarde, como pode ser visto na Tabela 1. Esse fenômeno é explicado por GOETZBERGER (1998), citado por RIFFEL (2005). Na Figura 10, indicam-se estas afirmações.

TABELA 1. Comportamento da eficiência do sistema em diferentes períodos. Efficiency system behavior for different day and season intervals.

\begin{tabular}{llcc}
\hline Dia & Período & Eficiência $(\%)$ & Temperatura $\left({ }^{\circ} \mathrm{C}\right)$ \\
\hline \multirow{2}{*}{$3-7-2005$} & Manhã & 9,58 & 35,34 \\
& Tarde & 9,34 & 42,83 \\
\hline \multirow{2}{*}{$16-11-2005$} & Manhã & 9,07 & 37,69 \\
& Tarde & 8,57 & 46,44 \\
\hline
\end{tabular}

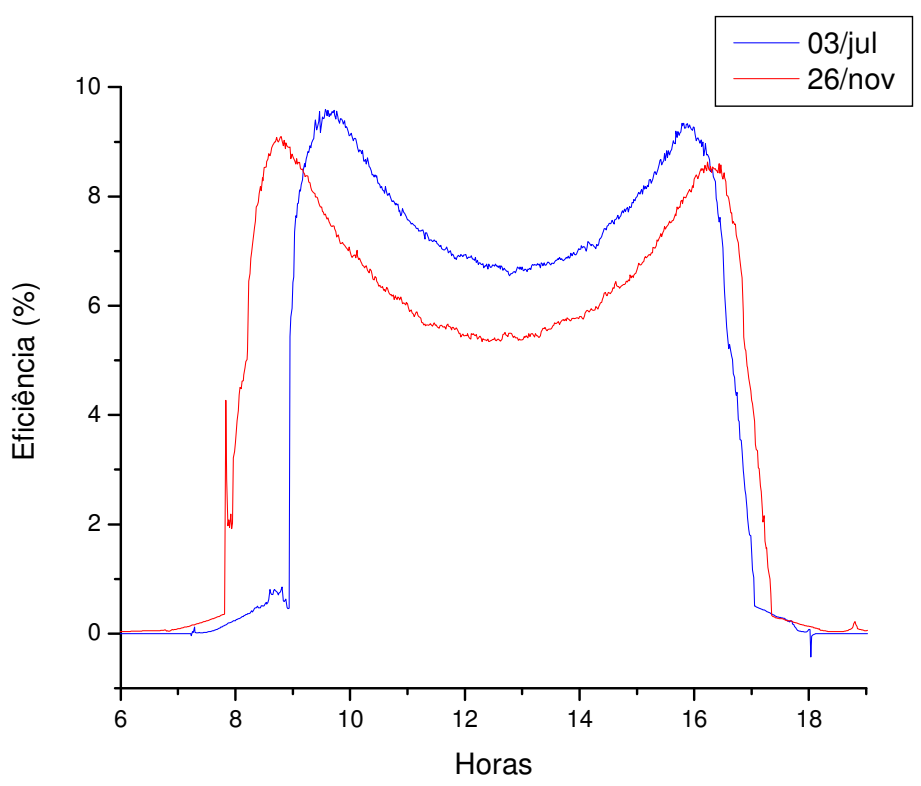

FIGURA 10. Eficiência do sistema de bombeamento de água. Efficiency for the water pumping system. 


\section{CONCLUSÕES}

As aplicações mais importantes de uma motobomba do porte utilizado neste estudo estão nas residências remotas distantes da rede elétrica, nos bebedouros para animais e na irrigação de culturas de baixo consumo de água.

Devido à realização do estudo no Sul do Brasil, conclui-se que o sistema pode bombear água em qualquer região com capacidade máxima de 53.053,51 L mês ${ }^{-1}$, ou seja, 1.768,45 L dia ${ }^{-1}$.

O sistema trabalhando em situação real de trabalho (bombeando água a $20 \mathrm{~m}$ de altura) apresentou eficiência máxima de $9,58 \%$ no solstício de inverno e valor mínimo de $8,57 \%$ no solstício de verão, levando-se em conta dias limpos, ou seja, sem a interferência de nuvens. Os dados deixam evidente que a temperatura influencia negativamente em sistemas fotovoltaicos.

\section{REFERÊNCIAS}

CAMUS, C.; EUSÉBIO, E. Gestão de energia: energia solar. Lisboa: Instituto Superior de Engenharia de Lisboa, Departamento de Engenharia Electrotecnica e Automação. 2006, 28 p.

CONAMA. CONSELHO NACIONAL DE MEIO AMBIENTE. Resolução CONAMA $n^{\circ} 001$ Estabelece a Definição de Impacto Ambiental. 1986 art $1^{\circ}$. p.1.

GNOATTO, E. Desempenho de painel fotovoltaico para geração de energia elétrica na região de Cascavel. 2003. 154 f. Dissertação (Mestrado em Engenharia de Sistemas Agroindustriais) Universidade Estadual do Oeste do Paraná, Cascavel, 2003.

GNOATTO, E.; FERRUZZI; Y.; RICIERI, R.P.; JUNIOR, M.M.; OLIVEIRA, T.E. Desempenho de painel fotovoltaico em um sistema isolado. In: ENCONTRO DE ENERGIA NO MEIO RURAL E GERAÇÃO DISTRIBUIDORA, 5., 2004, Campinas. Anais... Campinas: NIPE/UNICAMP, 2004. 1 CD-ROM.

KAWAHARA, J. Desempenho de uma motobomba acionada por um painel fotovoltaico. 2003. 98 f. Dissertação (Mestrado em Engenharia de Sistemas Agroindustriais) - Universidade Estadual do Oeste do Paraná, Cascavel, 2003.

KOLLING, M.E.; SOUZA, S.N.M.; RICIERI, R.P.; SAMPAIO, S.C.; DALLACORT, R. Análise operacional de um sistema fotovoltaico de bombeamento de água. Engenharia Agrícola, Jaboticabal, v.24, n.3, p.527-535, 2004.

LECT. LABORATÓRIO DE ENSINO DE CIÊNCIAS E TECNOLOGIA. Calculadora solar. Disponível em: <www.darwin.futuro.usp.br/site/sky/atividades/c_calculadora.htm>. Acesso em: 7 maio 2006.

METWALLY, H.M.B.; ANIS, W.R. Dynamic performance of directly coupled photovoltaic water pumping system using D.C. shunt motor. Energy Convers, Oxford, v.37, n.9, p.1.411-1.416, 1996.

RIFFEL, D.B. Unidade de osmose reversa acionada por energia solar fotovoltaica sem baterias: simulação, projeto e validação experimental. 2005. 125 f. Dissertação (Mestrado em Engenharia Elétrica) - Universidade Federal do Ceará, Fortaleza. 2005. 